\title{
Seasonal variations of nighttime D-region ionosphere in 2013 solar maximum observed from a low-latitude station
}

\author{
Le Minh Tan ${ }^{1 *}$, Nguyen Ngoc Thu ${ }^{2}$, Tran Quoc $\mathrm{Ha}^{3}$ and Quang Nguyen-Luong ${ }^{4}$
}

\begin{abstract}
We present the observation of tweek atmospherics with harmonics $m=1-8$ during the solar maximum year, 2013, at Tay Nguyen University, Vietnam (Geog. 12.65 $\mathrm{N}, 108.02^{\circ} \mathrm{E}$ ). The analysis of 33,690 tweeks on ten international quiet days during 2 months each season, summer (May, August), winter (February, November), and equinox (March, September), shows that tweeks occur about $51 \%$ during summer, $22 \%$ during winter, and $27 \%$ during equinox. The D-region ionosphere is more sharply bounded for harmonics $m=5-6$ around an altitude of $85.5 \mathrm{~km}$. The environment of the D-region is more inhomogeneous during winter and equinox seasons. The mean electron density varies from $28.4-225 \mathrm{~cm}^{-3}$, which corresponds to the harmonics $m=1-8$ at the mean reflection height of $81.5-87.7 \mathrm{~km}$. The results reveal that the lower reference height in our work as compared to other works is due to the higher level of solar activity. The equivalent electron density profile of the nighttime D-region ionosphere using tweek method during summer, equinox, and winter seasons shows lower values of electron density by $12-58 \%$, 3-67 \%, and 24-76\% than those obtained using the International Reference lonosphere (IRI-2012) model.
\end{abstract}

\section{Background}

Collisions between charged and neutral particles dominate the physical interaction of the D-region ionosphere $(\sim 60-90 \mathrm{~km})$. These activities play an important role in the propagation of the extremely low frequency (ELF; $3-3000 \mathrm{~Hz}$ ) and the very low frequency (VLF; $3-30 \mathrm{kHz})$ waves through the Earth-ionosphere waveguide (EIWG) (Hargreaves 1992; Kumar and Kumar 2013). By monitoring the ELF-VLF waves, Friedrich and Rapp (2009) showed that the nighttime D-region properties varies with zenith angle, solar flux, season, and latitude. The D-region ionosphere is too high for balloons and too low for the satellite measurements (Ohya et al. 2003). The attachment and recombination processes are too fast and that makes the free electron density very low $\left(<10^{3} \mathrm{~cm}^{-3}\right)$, especially in the nighttime. This inhibits the observability of the ionosondes and incoherent scatter radars (Hargreaves 1992). Rockets are used to measure the ionospheric parameters (Maeda 1971; Nagano and

\footnotetext{
*Correspondence: Imtan@ttn.edu.vn

${ }^{1}$ Department of Physics, Faculty of Natural Science and Technology, 567 Le

Duan, 632025 Buon Ma Thuot, Vietnam

Full list of author information is available at the end of the article
}

Okada 2000), but they are restricted by the timing of flights. Therefore, observing ELF-VLF from the ground is an effective tool to study the D-region ionosphere.

Lightning discharges emit ELF-VLF signals, which propagate into the EIWG and expose as "hooks" on the frequency-time spectrogram. They appear as chirping sounds on a loudspeaker. This type of sferics is called "tweeks" (Helliwell 1965; Yamashita 1978). Using the tweek method, many researchers have investigated the properties of the lower ionosphere. In the previous works, the first modes of tweeks are used to study the seasonal variations of the nighttime $\mathrm{D}$-region ionosphere during the low solar activity period (Maurya et al. 2012a,b). However, the seasonal variation of those parameters at higher harmonics is poorly understood, which limits our view of the overall morphology of the low-latitude D-region.

We observed tweeks at Tay Nguyen university, Vietnam (Geog. $12.65^{\circ} \mathrm{N}, 108.02^{\circ} \mathrm{E}$ ) during winter, equinox, and summer seasons of 2013 to calculate the cut-off frequency, reflection height, and electron density of the D-region ionosphere. From these parameters, we evaluate the morphology of this region. Our survey site is at low latitudes around the equatorial region, which is near the Asia

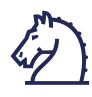

C 2015 Tan et al. Open Access This article is distributed under the terms of the Creative Commons Attribution 4.0 International License (http://creativecommons.org/licenses/by/4.0/), which permits unrestricted use, distribution, and reproduction in any medium, provided you give appropriate credit to the original author(s) and the source, provide a link to the Creative Commons license, and indicate if changes were made. 
Oceanic Region; hence, the lightning density is very high. This creates favorable opportunities to study the turbulence of the D-region using the ELF-VLF waves radiated by lightning. Furthermore, the observation period is during the high solar activity year of the solar cycle 24 , which we expect that the D-region perturbs much more violently. We present our experiment and data analysis method in section "Experimental data and analysis". In section "Results and discussion", we will discuss the results obtained over the year 2013 and compare them with the International Reference Ionosphere (IRI-2012) model. Finally, we draw out conclusion in section "Conclusions".

\section{Experimental data and analysis Experimental setup}

Our ELF-VLF receiver consists of a magnetic antenna, a preamplifier, an ADC (Analog to Digital Converter), a SU (Service Unit), a Global Positioning System (GPS) receiver, a PC, and recording software. The details of this receiver are described in our previous work (Tan et al. 2014). It has been developed to record the atmospheric signals. The antenna includes two orthogonal loops which are right isosceles triangles with the base of $2.6 \mathrm{~m}$. Each loop consists of 8 turns of 18 American Wire Gause copper wire. The surface of one loop orients in the north-south (N-S) direction, while the surface of other loop orients in the east-west (E-W) direction. If the magnetic component of electromagnetic waves changes and passes the loop of antennas, a voltage will be generated in the coils of the antenna (Ramo et al. 1994). In order to minimize signal interference, the loops are wrapped with the silver shields. The plane of the antenna which is perpendicular to E-W is chosen because it is very sensitive to sferics generated by lightning discharges (Dahlgren et al. 2011; Wood 2004). The signals from antenna are amplified and filtered by a preamplifier near the antenna and then transmitted by the coaxial cable to the ADC at a distance of $150 \mathrm{~m}$. The preamplifier is powered by a particular DC power supply to remove the AC noise. The ELF-VLF signals from the $\mathrm{E}-\mathrm{W}$ channel of the preamplifier go into the sound card. The SpectrumLab v2.77b22 records the sferics with audio files having extension "wav." The GPS is utilized for time synchronization with an accuracy of $100 \mathrm{~ns}$. To record the sferics, SpectrumLab is configured with the sample rate of $44.1 \mathrm{kHz}, 16$-bit sampling, and fast Fourier transform (FFT) input size of 512. The Sonic visualiser software developed by Cannam et al. (2010) is used to analyze the audio files.

\section{Data analysis}

Figure 1a-c shows the spectrograms on 22 February 2013 at 0:30 LT (local time (LT) $=\mathrm{UT}+7 \mathrm{~h}$ ), 13 March 2013 at 2:00 LT, and 15 May 2013 at 2:30 LT, respectively. Figure 1 shows the tweeks as the "hooks" appeared on the vertical lines. The third, fourth, and eighth harmonic tweeks clearly occurred on the spectrogram. The propagation of
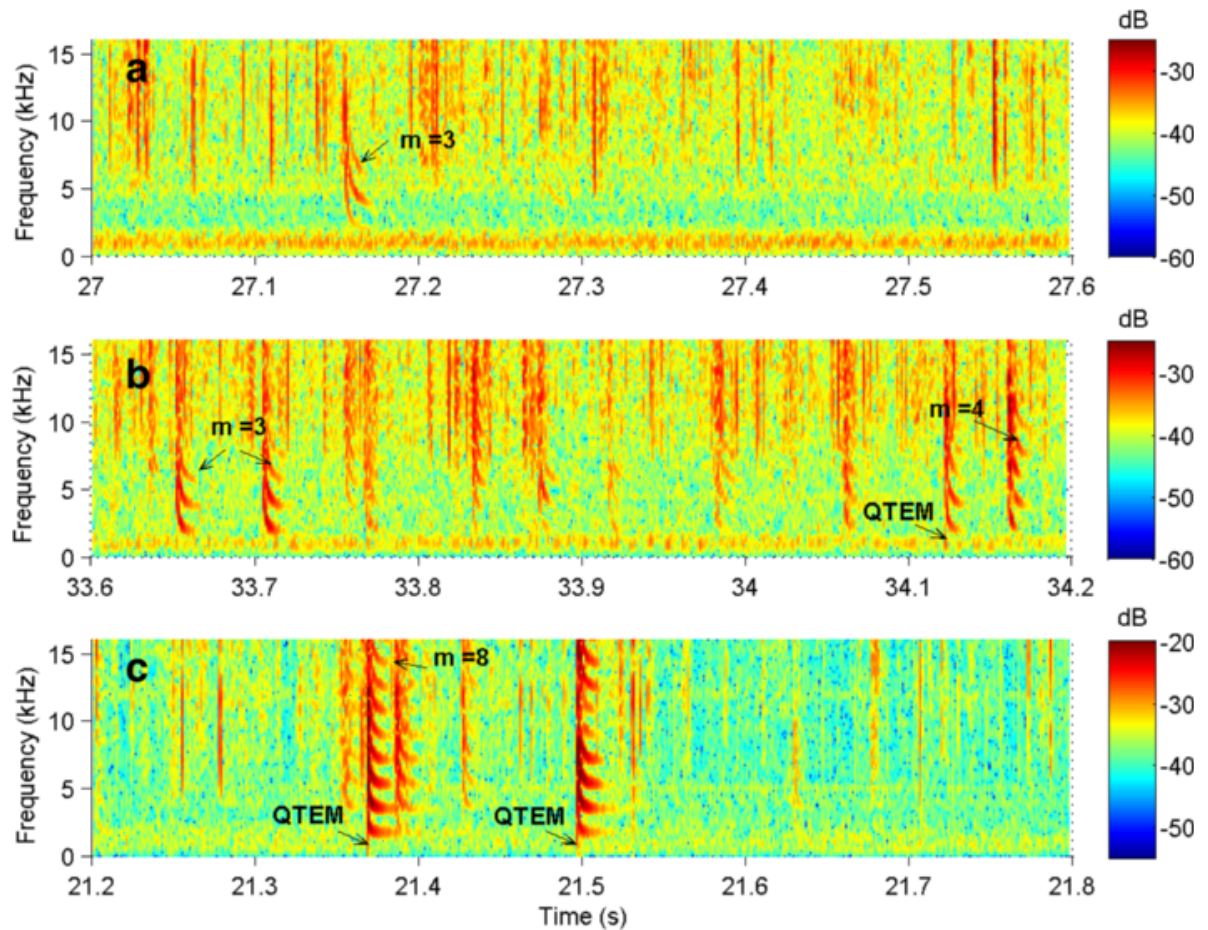

Fig. 1 Example of spectrograms showing the tweek events on 22 February 2013 at 0:30 LT (a), 13 March at 2:00 LT (b), and 15 May 2013 at 2:30 LT (c) 
ELF-VLF waves in the EIWG is analyzed in term of quasitransverse electric (QTE) and quasi-transverse magnetic (QTM) modes with the first mode cut-off frequency of about $1.8 \mathrm{kHz}$. The zero-order mode or quasi- transverse electromagnetic (QTEM) mode has the frequency components below the cut-off frequency of the first-order mode and its polarization is linearly polarized (Budden 1961; Hayakawa et al. 1994). The formation of tweeks near the mode cut-off frequency is examined by estimating the attenuation coefficient and excitation factor of waveguide for QTM and QTE modes (Yamashita 1978). For frequencies less than $15 \mathrm{kHz}$, the lower order QTM and QTE modes approximate pure TM and TE modes (Wood 2004). We therefore treat the modes in the EIWG as pure TM modes. The QTEM modes below the first mode cut-off frequency are shown in the spectrograms (Fig. 1). The broadband data are recorded for a duration of $2 \mathrm{~min}$ at every $15 \mathrm{~min}$ interval. The tweeks were recorded on ten international quiet days during 2 months each season: summer (May, August), winter (February, November), and equinox (February, September). Tweeks rarely appear during sunset, 10:00-12:00 UT (17:00-19:00 LT) and during sunrise, 22:00-24:00 UT (05:00-07:00 LT). Therefore, we consider only tweeks obtained during the period from 12:00-22:00 UT (19:00-5:00 LT). All clearly visible tweeks were selected with the intensity levels $\geq-35 \mathrm{~dB}$ as seen in the spectrogram. The cut-off frequency captured from tweeks during three seasons is used to estimate the parameters of the lower ionosphere.

We used the method of Ohya et al. (2003) to estimate the electron density of the nighttime D-region ionosphere via the following equation:

$$
n_{e}=1.241 \times 10^{-8} f_{p}\left(f_{p}+f_{H}\right)
$$

where $f_{H}$ is the gyrofrequency and $f_{p}$ is the plasma frequency. Considering the low-latitude $\left(30^{\circ} \mathrm{N}-30^{\circ} \mathrm{S}\right)$ location of our site, we assume $f_{H}=1.3 \pm 0.16 \mathrm{MHz}$ by using the IGRF (International Geomagnetic Reference Field) model. This result is consistent with the results calculated by Saini and Gwal (2005) and Kumar et al. (2009).

Assuming that $f_{p}<<f_{H}$ and the wave experience of reflection, i.e. $f_{c}=f_{p}$, we obtain:

$$
n_{e}=1.241 \times 10^{-8} f_{c} f_{H}
$$

Substituting the value of $f_{H}$ in Eq. (2), we obtain:

$$
n_{e}=1.6133 \times 10^{-2} f_{c}
$$

The reflection height $h$ of the EIWG is determined from the cut-off frequency for each mode as (Budden 1961):

$$
h=\frac{c m}{2 f_{c m}}
$$

where $c$ is the speed of light in free space, $m$ is the mode number and $f_{c m}$ is cut-off frequency.
The group velocity $v_{g m}$ in the homogeneous spherical EIWG is given by (Ohya et al. 2008; Maurya et al. 2012b):

$$
v_{g m}=c\left(1-f_{c m}^{2} / f^{2}\right)^{1 / 2} /\left(1-c / 2 R f_{c m}\right)
$$

where $\mathrm{R}$ is the radius of the Earth.

Equation (5) shows that as $f$ reaches near $f_{c m}, v_{g m}$ approaches zero, while as $f$ becomes much larger than $f_{c m}, v_{g m}$ approaches the speed of light. In the case of $f$ is less than cut-off frequency, the radio wave is quickly attenuated along the propagation distance (Wood 2004).

The propagation distance of tweek sferics is obtained by (Ohya et al. 1981):

$$
d=\frac{\left|t_{2}-t_{1}\right|\left(v_{g 1} \times v_{g 2}\right)}{\left|v_{g 1}-v_{g 2}\right|}
$$

where $t_{2}-t_{1}$ is the difference in arrival times of the two frequencies, $f_{2}$ and $f_{1}$, close to the tweeks of any mode, and $v_{g f 1}$ and $v_{g f 2}$ are the corresponding group velocities of the radio waves centered at frequencies $f_{1}$ and $f_{2}$.

The cut-off frequency captured from tweeks during three seasons is used to estimate the ionospheric refection height and D-region electron density at the reflection height. The arrival times $t_{1}$ and $t_{2}$ of two frequencies $f_{1}$ and $f_{2}$ closed to cut-off frequency from tweek spectrograms were measured to estimate the propagation distance of the tweeks. The frequency and time resolutions of measurement are $35 \mathrm{~Hz}$ and $1 \mathrm{~ms}$, respectively. The estimated error in the reflection height is about $1.5 \mathrm{~km}$ for first-order mode, and it reduces with the increase in the modes. The errors in the electron density and propagation distance for all modes are found to be $\sim 0.6 \mathrm{~cm}^{-3}$ and $\sim 470 \mathrm{~km}$, respectively.

\section{Results and discussion}

\section{Tweek occurrence observed at low latitudes}

Table 1 presents a total of 33,690 tweeks with $m=1-8$ observed at Tay Nguyen University, a low-latitude site. Seven thousand four hundred fourteen (22\%), 8974 (27\%), and 17302 (51\%) tweeks were captured during winter, equinox, and summer seasons, respectively. We found that the mean tweek's duration varies from 8-43 ms. Maurya et al. (2012a) found that tweek duration is about $8-48 \mathrm{~ms}$ for tweeks observed at the other lowlatitude stations, Allahabad and Nainital (India). Kumar et al. (2008) recorded tweeks at Suva (Fiji) and estimated the duration of tweeks varies from 15-60 ms. Our results on the mean tweek's duration show lower than those reported by those authors because our survey site is located in the Asian storm center; hence, many sources of tweeks are around the station. The higher harmonic tweeks often occurred during summer season, whereas lower harmonic tweeks mainly occurred during equinox and winter seasons (Table 1). The occurrences of different harmonic tweeks are not much different between 
Table 1 Tweek occurrence observed during winter, equinox, and summer seasons

\begin{tabular}{|c|c|c|c|c|c|c|c|c|c|c|}
\hline & & \multicolumn{8}{|c|}{ Harmonic tweeks } & \multirow{2}{*}{ Total } \\
\hline & & $1 s t$ & 2nd & $3 r d$ & 4 th & 5 th & 6th & 7 th & 8th & \\
\hline \multirow[t]{2}{*}{ Winter } & & 828 & 3669 & 1844 & 727 & 228 & 72 & 38 & 8 & 7414 \\
\hline & \%Count & 11.17 & 49.49 & 24.87 & 9.81 & 3.08 & 0.97 & 0.51 & 0.11 & 100 \\
\hline \multirow[t]{2}{*}{ Equinox } & & 79 & 2281 & 3025 & 1580 & 1011 & 561 & 309 & 128 & 8974 \\
\hline & \%Count & 0.88 & 25.42 & 33.71 & 17.61 & 11.27 & 6.25 & 3.44 & 1.43 & 100 \\
\hline \multirow{2}{*}{ Summer } & & 249 & 2511 & 4465 & 4595 & 3068 & 1395 & 727 & 292 & 17302 \\
\hline & \%Count & 1.44 & 14.51 & 25.81 & 26.56 & 17.73 & 8.06 & 4.20 & 1.69 & 100 \\
\hline
\end{tabular}

pre-midnight and post-midnight (Table 2). During winter season, the second harmonic tweeks are most popular (50\%). During equinox season, the third harmonic tweeks dominate $(34 \%)$. During summer season, the fifth harmonic tweeks are most often (27\%). In all cases, the higher harmonic tweeks occurred rarely, especially eighth harmonic tweeks. Kumar et al. (2008) found that the attenuation of ELF-VLF waves in the D-region increases for the higher modes. Therefore, it suggests that the absorption of the D-region is stronger for higher modes during winter and equinox seasons as compared to that during summer season.

Figure 2 shows that most tweeks occurred with the propagation distance in the range of $2000-3000 \mathrm{~km}$. The occurrence rate of tweeks with the propagation distance in the range of 1000-5000 km during equinox, winter, and summer seasons varies about 92,89 , and $92 \%$, respectively. Tweeks with the propagation distance in the range of 1000-2000 km occurred more often during summer as compared to those during equinox and winter. Observing tweeks at a low-latitude station, Kumar et al. (2008) reported that $90 \%$ of tweek propagation distance are in the range of $1000-5000 \mathrm{~km}$ with maximum in the range of 2000-3000 km. Overall, our results in the tweek propagation distance are in accordance with those reported by Kumar et al.(2008). Maurya et al. (2010) and Kumar et al. (2008) found that the propagation distances are up to $12,000 \mathrm{~km}$ and also illustrated that the attenuation offered by EIWG is higher for tweeks with higher modes. Thus, these tweeks from propagating larger distance are limited. At our site, during the equinox, we can record a maximum propagation distance of $12,000 \mathrm{~km}$. The majority of the direction of propagation of tweeks came from east to west, as most of tweeks came from over the sea which is in the east of our site. The propagation of ELF-VLF waves over the sea undergoes less attenuation as compared to that over the land (Ohya et al. 1981).

\section{The variations of reflection height and fundamental frequency with mode number}

We consider tweeks with the propagation distance less than $5000 \mathrm{~km}$ to avoid the errors caused by the daytime propagation path particularly for tweeks coming from East to West directions (Maurya et al. 2012a). Table 3 gives an example of calculation (see also Fig. 1). The results show that the reflection height $(h)$ varies from $70.3-83.2 \mathrm{~km}$, the electron density $\left(n_{e}\right)$ changes in the range of $29.4-234.7 \mathrm{~cm}^{-3}$, and the mean fundamental frequency $\left(f_{c m} / m\right)$ varies within $1.8-2.1 \mathrm{kHz}$. In addition, the propagation distance $(d)$ varies from $648-3553 \mathrm{~km}$.

From Fig. 3a, it can be seen that the mean $h$ during winter, equinox and summer seasons varies between $84.2-87.0 \mathrm{~km}, 83.9-87.6 \mathrm{~km}$ and $84.3-86.4 \mathrm{~km}$, respectively. Overall, the mean $h$ during three seasons increases sharply from $m=1$ to $m=4$, then stays constant up to $m=5$, and increase linearly to $m=8$. The mean $h$ increases as the harmonics of tweeks increases, which means that the higher harmonics of the same tweeks penetrate deeper into the nighttime lower ionosphere while reaching to the receiving station by multiple reflections (Kumar et al. 2008). Tweeks are reflected at the altitudes where the plasma frequency equals the individual cut-off frequency of each harmonic, and therefore the waves with the higher harmonics are reflected at higher altitude due to the plasma frequency is higher (Shvets and Hayakawa 1998). We fit a linear function to the mean reflection

Table 2 Tweek occurrence in the pre-midnight and post-midnight periods

\begin{tabular}{|c|c|c|c|c|c|c|c|c|c|c|}
\hline & & Harm & weeks & & & & & & & \\
\hline & & $1 s t$ & 2nd & $3 r d$ & 4 th & 5 th & 6th & 7 th & 8th & Total \\
\hline Pre- & & 573 & 4090 & 4407 & 3440 & 2177 & 1072 & 579 & 283 & 16621 \\
\hline midnight & $\%$ Count & 3.45 & 24.61 & 26.51 & 20.70 & 13.10 & 6.45 & 3.48 & 1.70 & 100 \\
\hline Post- & & 583 & 4371 & 4927 & 3462 & 2130 & 956 & 495 & 145 & 17069 \\
\hline midnight & $\%$ Count & 3.42 & 25.61 & 28.87 & 20.28 & 12.48 & 5.60 & 2.90 & 0.85 & 100 \\
\hline
\end{tabular}




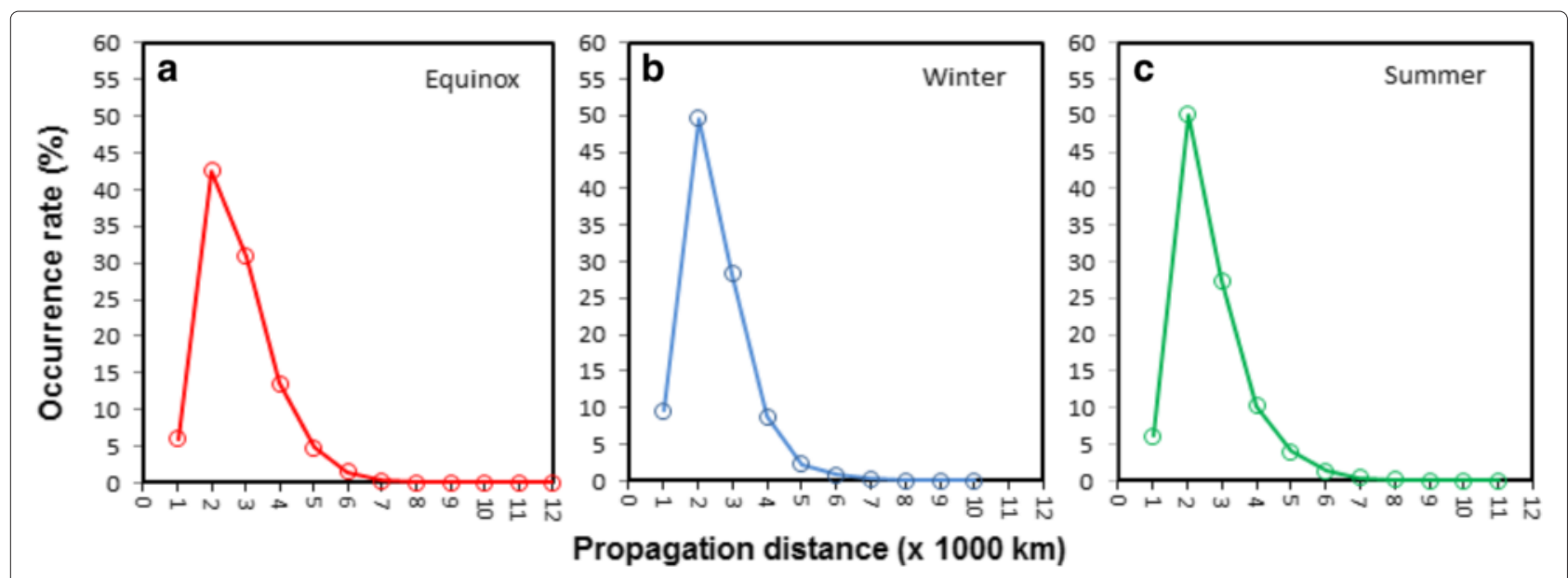

Fig. 2 Tweek occurrence rates as a function of the propagation distance for the equinox (a), winter (b), and summer seasons (c)

Table 3 The mode number $(m)$, the mean fundamental frequency $\left(f_{c m} / m\right)$, reflection height $(h)$, propagation from lightning discharges to the receiver $(d)$, and electron density $\left(n_{e}\right)$ obtained from tweeks on the spectrograms (a-c) of Fig. 1

\begin{tabular}{|c|c|c|c|c|c|}
\hline Spectrogram & $\begin{array}{l}\text { Mode } \\
\text { number } \\
(m)\end{array}$ & $\begin{array}{l}\text { Mean } \\
\text { fundamental } \\
\text { frequency }(\mathrm{Hz})\end{array}$ & $\begin{array}{l}\text { Reflection } \\
\text { height } \\
(\mathrm{km})\end{array}$ & $\begin{array}{l}\text { Propagation } \\
\text { distance } \\
(\mathrm{km})\end{array}$ & $\begin{array}{l}\text { Electron } \\
\text { density } \\
\left(\mathrm{cm}^{-3}\right)\end{array}$ \\
\hline \multirow[t]{3}{*}{ a } & 1 & 1980 & 75.8 & 3553 & 31.9 \\
\hline & 2 & 1974 & 76.0 & 1576 & 63.7 \\
\hline & 3 & 1902 & 78.9 & 1492 & 92.1 \\
\hline \multirow[t]{10}{*}{$b$} & 1 & 1825 & 82.2 & 1672 & 29.4 \\
\hline & 2 & 1896 & 79.1 & 1243 & 61.2 \\
\hline & 3 & 1902 & 78.9 & 1375 & 92.1 \\
\hline & 1 & 1825 & 82.2 & 1541 & 29.4 \\
\hline & 2 & 1896 & 79.1 & 1680 & 61.2 \\
\hline & 3 & 1920 & 78.1 & 1298 & 92.9 \\
\hline & 1 & 2135 & 70.3 & 1060 & 34.5 \\
\hline & 2 & 1922 & 78.1 & 1540 & 62.0 \\
\hline & 3 & 1971 & 76.1 & 946 & 95.4 \\
\hline & 4 & 1945 & 77.1 & 1187 & 125.5 \\
\hline \multirow[t]{8}{*}{ c } & 1 & 1841 & 81.5 & 2787 & 29.7 \\
\hline & 2 & 1843 & 81.4 & 2228 & 59.5 \\
\hline & 3 & 1826 & 82.1 & 1011 & 88.4 \\
\hline & 4 & 1804 & 83.2 & 1486 & 116.4 \\
\hline & 5 & 1834 & 81.8 & 959 & 148.0 \\
\hline & 6 & 1809 & 82.9 & 1078 & 175.1 \\
\hline & 7 & 1814 & 82.7 & 941 & 204.9 \\
\hline & 8 & 1818 & 82.5 & 648 & 234.7 \\
\hline
\end{tabular}

height and mode number relation. The trend of variation of $h$ with mode number for winter is $h_{\text {winter }}=0.50 \mathrm{~m}+$ 83.0 with $R^{2}=0.83$, for equinox is $h_{\text {equinox }}=0.56 \mathrm{~m}+$ 82.8 with coefficient of determination $R^{2}=0.94$, and for summer seasons is $h_{\text {summer }}=0.18 m+84.7$ with $R^{2}=0.49$. The slope of the linear function is lower during summer season (0.18) as compared to that during winter $(0.50)$ and equinox (0.56) seasons. Figure 3a shows that tweeks with $m=5$ and 6 are reflected at the same altitude for all seasons. Theoretically, for a waveguide with perfectly conducting boundaries, the higher modes can be reflected at the same altitude. Since the conductivity of the boundary is not perfect, the higher modes are reflected at the higher altitude (Maurya et al. 2012a). Therefore, the Dregion ionosphere is less inhomogeneous for harmonics $m=5-6$ around an altitude of $85.5 \mathrm{~km}$.

Figure $3 \mathrm{~b}$ shows the variation of $f_{\mathrm{cm}} / \mathrm{m}$ with the harmonics $m$. It reveals that $f_{c m} / m$ during winter, equinox and summer seasons slightly reduces from 1.81-1.72, $1.81-1.71$, and $1.79-1.74 \mathrm{kHz}$, respectively. The trend of reduction of $f_{\mathrm{cm}} / \mathrm{m}$ with mode number for winter is $f_{\text {winter }}=-11.60 m+1816$ with $R^{2}=0.85$, for equinox is $f_{\text {equinox }}=-13.08 m+1823$ with $R^{2}=0.96$, and for summer is $f_{\text {summer }}=-5.17 m+1782$ with $R^{2}=0.58$. The variation of $f_{\mathrm{cm}} / \mathrm{m}$ is less steep during summer season as compared to that during winter and equinox seasons.

\section{Morphology of nighttime D-region ionosphere}

Each panel in Fig. 4 presents the temporal variation of the reflection height with different harmonics. The mean $h$ varies from 81.5 to $87.7 \mathrm{~km}$ for $m=1-8$. The mean value of $n_{e}$ increases from $28.4-225.0 \mathrm{~cm}^{-3}$ in the altitude range of $81.5-87.7 \mathrm{~km}$. During winter season (February and November), the variation of $h$ makes a dip around 22:00 LT and has a crest around 3:00 LT, and then it slightly decreases. During summer (May and 


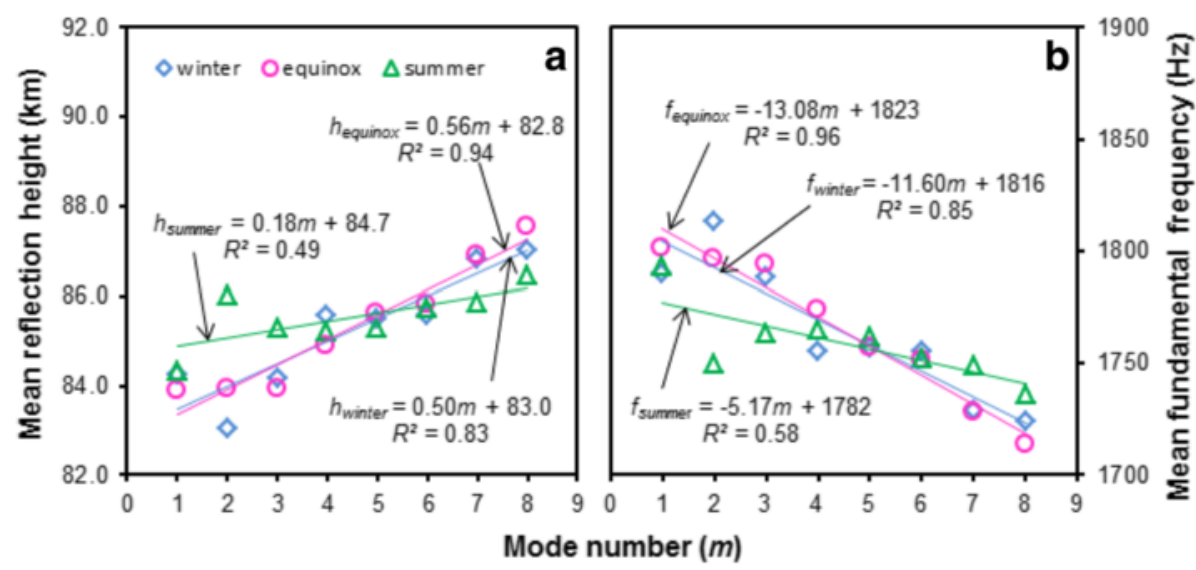

Fig. 3 The variation of the mean reflection height (a) and equivalent cut-off frequency (b) with mode number during different seasons: winter (blue diamonds), equinox (pink circles), and summer (green triangles)

August), the temporal variation of $h$ has the crest around 20:30 LT and reduces to the dip from 1:00-2:00 LT and then increases. During equinox season, the $h$ decreases from 19:00-23:00 LT for March 2013 and increases from 19:00-21:00 LT for September 2013. The trend of the variation of $h$ on panels (a) and (c), (b) and (d), and (e) and (f) is nearly symmetric. In other words, there is the near opposite of reflection height variation between the two seasons. The differences of $h$ for higher harmonics during summer season are not significant (Fig. 5). This reveals that the Dregion is more delicate and homogeneous during summer as compared to that during winter and equinox seasons.

To present the seasonal variation of $h$ for different modes, the data was smoothed by using the AdjacentAveraging method with 5 points of window (Fig. 5). In the pre-midnight, the $h$ for $m=1-6$ is higher during summer season as compared to that during winter and equinox seasons. In the post-midnight, the seasonal variation of $h$ for $m=2-3$ is not significant, and the $h$ for $m=4-6$ is lower during summer season as compared to that during winter and equinox seasons. The trend of variation of $h$ for the first harmonic is not clear because lower harmonics may interfere with AC noise. The increase of $h$ at nighttime corresponds to the decrease of electron density due to its loss by the attachment and recombination processes. The scattered Lyman- $\alpha$ is an important source of the Dregion ionization. Ohya et al. (2011) found that about $67 \%$ of the nighttime D-region ionization is caused by Lyman$\alpha$ and Lyman $\beta$ which ionize $\mathrm{NO}$ and $\mathrm{O}_{2}$ at altitude of $95 \mathrm{~km}$. The lower $h$ in the pre-midnight period during

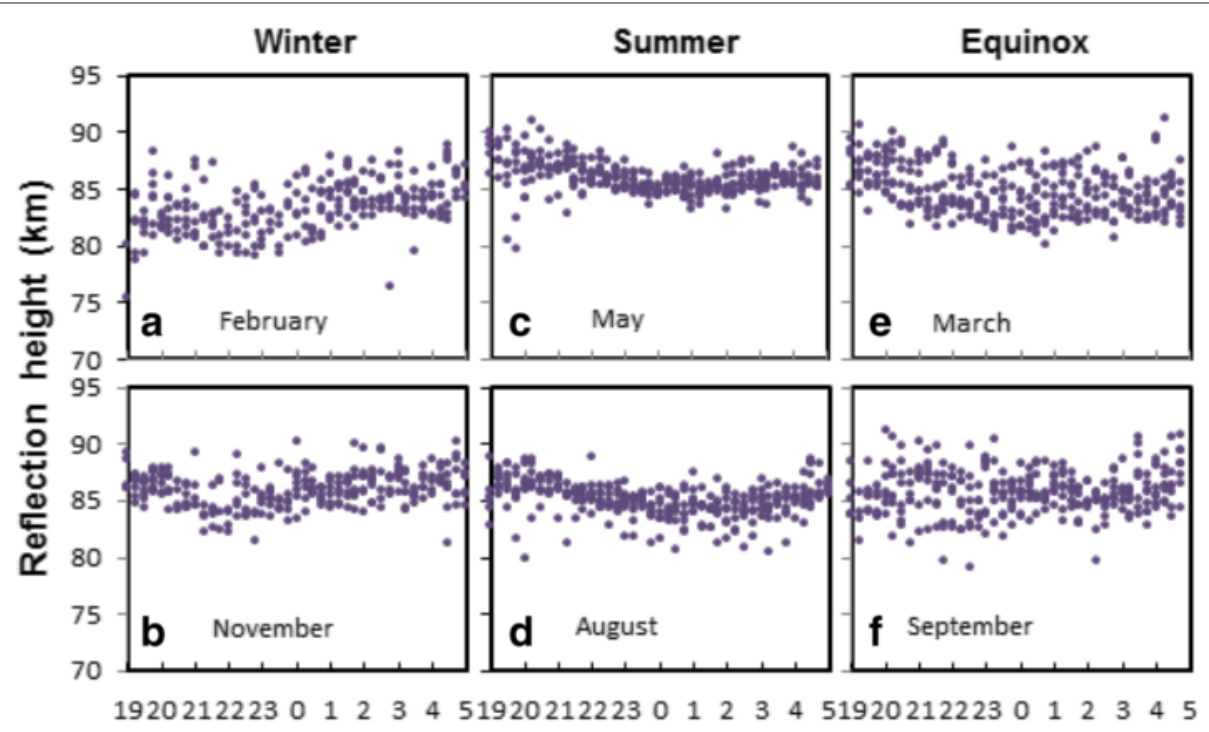

Time LT (hours)

Fig. 4 The temporal variation of reflection height in winter $(\mathbf{a}, \mathbf{b})$, summer $(\mathbf{c}, \mathbf{d})$ and equinox $(\mathbf{e}, \mathbf{f})$ of 2013 


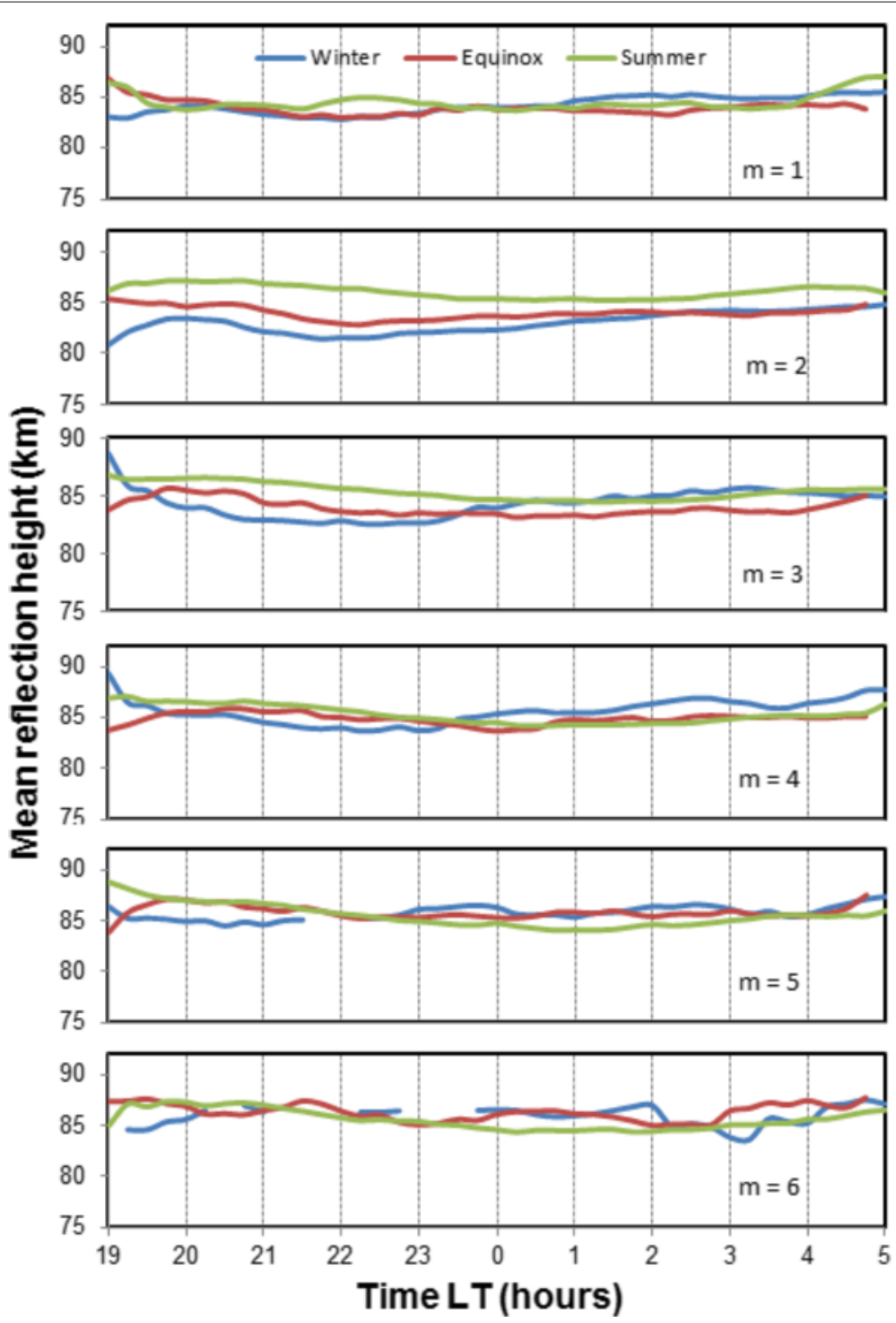

Fig. 5 Comparison of mean reflection heights for the different harmonics during winter (blue line), equinox (yellow line), and summer (green line) seasons

winter as compared to equinox and summer seasons is explained by the fact that the lower $n_{e}$ of daytime during winter giving rise to slower the loss processes of electrons in the pre-midnight period (Maurya et al. 2012b). Those phenomena clearly show at lower altitudes of the D-region. The $h$ for $m=4-6$ in the post-midnight period is higher during winter and equinox seasons as compared to that during summer season. It can be explained that tweek with higher modes could reflect at the less different altitudes because the D-region during summer season becomes less inhomogeneous. Around 19:00 LT, the tweek reflection height during winter season is higher than that during summer for $m=3-4$. The higher $h$ of winter after sunset transition could be caused by lower daytime $n_{e}$ during winter season.
Recording tweeks with a maximum up to the eighth harmonics from January-April, $1991\left(R_{z}=140\right)$, Shvets and Hayakawa (1998) calculated $h$ which varies from 81-83 km. Capturing tweeks with $m=1-6$ during the period of September, 2003-July, 2004 $\left(R_{z}=45\right)$ at Suva (Geog. 18.2 S; 178.3 E), Kumar et al. (2008) found that $h$ varied from $83-92 \mathrm{~km}$. At a low-latitude station, Allahabad (India), Maurya et al. (2012a) observed tweeks with $m=1-6$ from April, $2007\left(R_{z}=7.5\right)$ to March 2008 $\left(R_{z}=2.9\right)$, the mean $h$ increased from $80-95 \mathrm{~km}$. In our work, the mean $h$ varies from $81.5-87.7 \mathrm{~km}$, which is higher than that reported by Shvets and Hayakawa (1998), but lower than that shown in the results of Kumar et al. (2008) and Maurya et al. (2012a). Shvets and Hayakawa (1998) indicated that when the Sun's activity decreases 
hence the reflection height increases. Bremer and Singer (1977) and Danilov (1998) also illustrated that the Sun's activities affect the electron density of the nighttime Dregion. Surveying the seasonal variation of tweek reflection height over three solar cycles, Ohya et al. (2011) found that the reflection height was relatively low in March-April and high in July-October.

\section{The seasonal variation of Wait's parameters and electron density profiles}

Using first three modes of tweeks, Kumar et al. (2009) and Maurya et al. (2012a) calculated the reference height $\left(h^{\prime}\right)$ and sharpness factor $(\beta)$ by using the Wait's formula. Maurya et al. (2012a) used two tweeks in $1 \mathrm{~min}$ at each 15 min interval during pure nights from 21:00-02:00 LT of 2010, meanwhile, Kumar et al. (2009) used tweeks in 5 min at each hour interval during nights from 21:00-03:00 LT. In present work, we use the previous method of Kumar et al. (2009) and Maurya et al. (2012a) to obtain $h^{\prime}$ and $\beta$. We calculated the mean $h$ and $n_{e}$ of the first three harmonics of tweeks recorded in 2 min at every 15 min interval. We analyzed tweeks in August, September, and November of 2013, as representative of summer, equinox, and winter seasons. Tweeks having $d$ less than $5000 \mathrm{~km}$ observed from 21:00-02:00 LT are chosen, so that the error contribution due to in the pre-midnight period, some tweeks coming from dayside part (from west side of the station) and in post-midnight period, some tweeks coming from dayside part (from east side of the station) is avoided.

In Table 4, results reveal that $h^{\prime}$ during winter, equinox, and summer seasons varies between $82.2-86.9 \mathrm{~km}$ with a mean value of $84.4 \pm 1.5 \mathrm{~km}, 81.1-86.9 \mathrm{~km}$ with a mean value of $83.7 \pm 1.5 \mathrm{~km}$, and $81.2-87.5 \mathrm{~km}$ with a mean value of $83.3 \pm 1.8 \mathrm{~km}$, respectively. The $\beta$ during winter, equinox, and summer seasons varies between $0.49-0.65 \mathrm{~km}^{-1}$ with a mean value of $0.57 \pm 0.07 \mathrm{~km}^{-1}$, $0.46-0.66 \mathrm{~km}^{-1}$ with a mean value of $0.55 \pm 0.06 \mathrm{~km}^{-1}$, $0.43-0.66 \mathrm{~km}^{-1}$ with a mean value of $0.55 \pm 0.06 \mathrm{~km}^{-1}$, respectively. The $h^{\prime}$ is lower during summer season as compared to that during winter and equinox season. The $\beta$ is higher during winter season as compared to that during summer and equinox seasons.

Table 4 The values of reference height and sharpness factor during winter, equinox and summer seasons

\begin{tabular}{lllllll}
\hline \multirow{2}{*}{ Values } & \multicolumn{3}{c}{ Winter } & \multicolumn{2}{c}{ Equinox } & \multicolumn{2}{c}{ Summer } \\
& $h^{\prime}(\mathrm{km})$ & $\beta\left(\mathrm{km}^{-1}\right)$ & $h^{\prime}(\mathrm{km})$ & $\beta\left(\mathrm{km}^{-1}\right)$ & $h^{\prime}(\mathrm{km})$ & $\beta\left(\mathrm{km}^{-1}\right)$ \\
\hline Min & 82.2 & 0.49 & 81.1 & 0.46 & 81.2 & 0.43 \\
Max & 86.9 & 0.65 & 86.9 & 0.66 & 87.5 & 0.66 \\
Mean & 84.4 & 0.57 & 83.7 & 0.55 & 83.3 & 0.55 \\
SD & \pm 1.5 & \pm 0.07 & \pm 1.5 & \pm 0.06 & \pm 1.8 & \pm 0.06 \\
\hline
\end{tabular}

Observing tweeks at Allahabad, India $\left(16.05^{\circ} \mathrm{N}\right)$ during the low solar activity period, Maurya et al. (2012a) found that the mean $h^{\prime}$ during winter, equinox, and summer seasons are $85.9,85.7$, and $83.5 \mathrm{~km}$, respectively, and the mean $\beta$ during winter, equinox, and summer seasons are $0.51,0.54$, and $0.61 \mathrm{~km}^{-1}$, respectively. In our work, the mean $h^{\prime}$ during three seasons is lower by $0.2-2.2 \mathrm{~km}$ than that reported by Maurya et al. Our mean $\beta$ is higher by 0.06 and $0.01 \mathrm{~km}^{-1}$ during winter and equinox seasons but lower by $0.06 \mathrm{~km}^{-1}$ during summer season than those reported by Maurya et al. (2012a), respectively. Cummer et al. (1998) observed sferics at mid-latitude of $37.43^{\circ} \mathrm{N}$ in July $1996\left(R_{z}=10\right)$ and used the Long Wave Propagation Capability (LWPC) program to calculate $h^{\prime}$ and $\beta$ with 83.3 and $0.49 \mathrm{~km}^{-1}$, respectively. Using LWPC modeling of amplitude and phase of VLF signals, Thomson et al. (2007) studied the nighttime mid-latitude D-region near solar minimum and estimated the Wait's parameters of $h^{\prime}=85.1 \mathrm{~km}$ and $\beta=0.63 \mathrm{~km}^{-1}$. Cheng et al. (2006) recorded sferics during 16 nights of summer season at Duke $\left(36^{\circ} \mathrm{N}\right)$ and found that $h^{\prime}$ and $\beta$ varied from $83.6-85.6 \mathrm{~km}$ and $0.4-0.5 \mathrm{~km}^{-1}$, and the mean $h^{\prime}$ and $\beta$ are $84.5 \mathrm{~km}$ and $0.45 \mathrm{~km}^{-1}$, respectively. Our results on $h^{\prime}$ during summer are lower than those reported by those authors.

Figure 6 presents the seasonal variation of electron density profiles obtained by different methods. In order to plot the electron density from the IRI model, we selected five quiet days corresponding to five observing nights during August, September, and November of 2013 and obtained the $n_{e}$ in the altitude range of $80-100 \mathrm{~km}$ at the midnight $(0: 00 \mathrm{LT})$. The values of $n_{e}$ calculated by tweek method during summer, equinox, and winter seasons are lower by $12-58 \%, 3-67 \%$, and $24-76 \%$ than those obtained by IRI-2012 model, respectively, and show a good comparison with IRI-2012 in the altitude ranges of $82-89 \mathrm{~km}, 87-92 \mathrm{~km}$, and $88-93 \mathrm{~km}$ for summer, equinox, and winter seasons, respectively. Observing the nighttime D-region during March-December 2006 at Suva $\left(18.2^{\circ} \mathrm{S}\right.$ $178.3^{\circ}$ E) Fiji, Kumar et al. (2009) found that the values of $n_{e}$ obtained by tweek method are lower by $20-45 \%$ at altitudes $82-86 \mathrm{~km}$ than those obtained by IRI2001 model. Observing tweeks during $2010\left(R_{z}=16.5\right)$, Maurya et al. (2012a) found that the $n_{e}$ of the nighttime lower ionosphere shows lower by $5-60 \%$ than that obtained using IRI-2007 model at low-latitude stations and also concluded that tweek method shows significant seasonal variation in $n_{e}$, whereas IRI-2007 model does not have any significant seasonal variation. Our results in the values of $n_{e}$ of the electron density profile at the altitude range of 80-88 km during summer season show a good comparison with results reported by Maurya et al. However, the values of $n_{e}$ in our results during winter and equinox seasons are significantly higher by $3-26,841 \mathrm{~cm}^{-3}$ and 


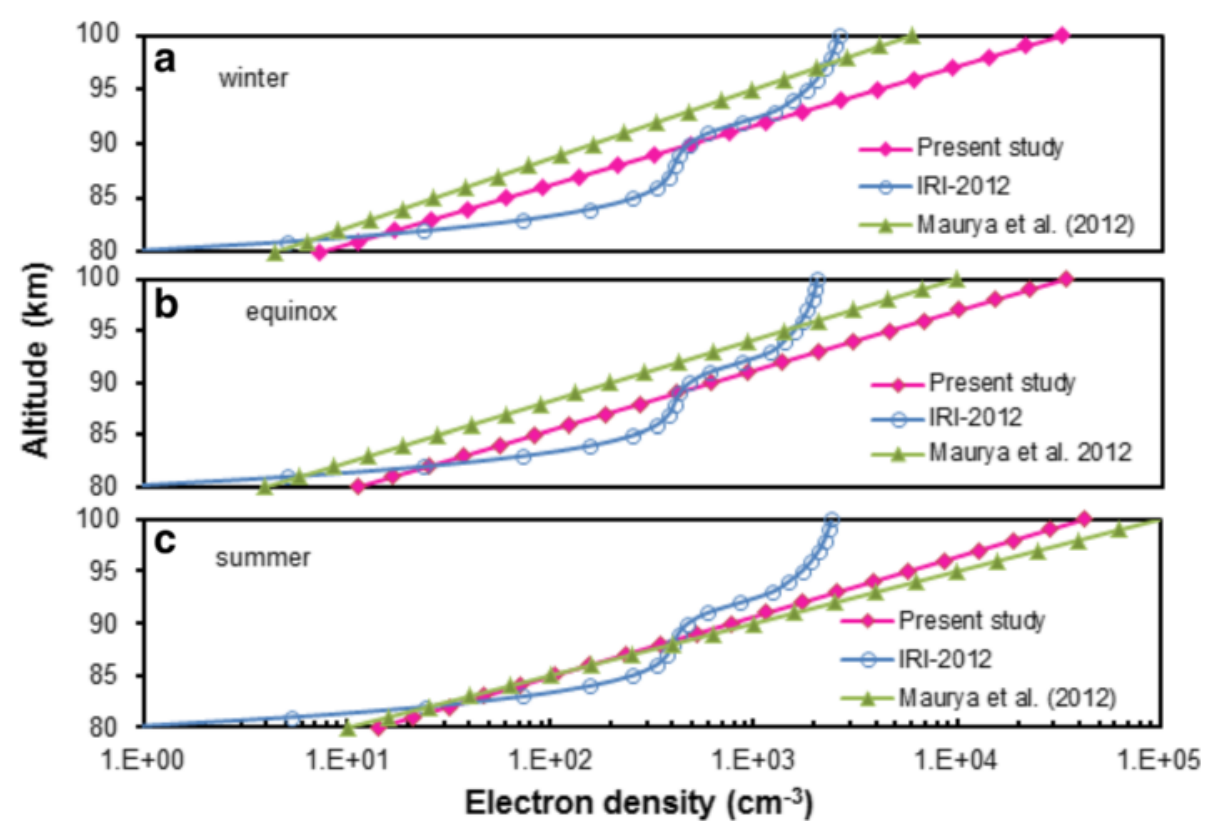

Fig. 6 The electron density profile obtained using tweek method (pink line and diamonds), the IRI-2012 model (blue line and circles) and the results obtained at Allahabad, India (Maurya et al. 2012a) (green line and triangles) during winter (a), equinox (b), and summer (c) seasons

$7-23,818 \mathrm{~cm}^{-3}$ than those found by Maurya et al. (2012a). This explains that the higher solar activity increases the electron density, and hence, decreases the reference height of the nighttime D-region. We also found that the deviations of $n_{e}$ between summer and winter vary from 7-9912 $\mathrm{cm}^{-3}$ and $6-94,449 \mathrm{~cm}^{-3}$ for our result and Maurya et al.'s result, respectively. The deviations of $n_{e}$ between summer and equinox vary from $3-9167 \mathrm{~cm}^{-3}$ and $6-90681 \mathrm{~cm}^{-3}$ for our result and Maurya et al.'s result (Maurya et al. 2012a), respectively. This is probably due to the variation of Galactic Cosmic Rays in different solar periods. Thomson et al. (2012a) reported that GCRs is another important source of ionization of the nighttime D-region, which has nearly half of the ionization rate of Lyman- $\alpha$ at $85 \mathrm{~km}$ altitude. The intensity of GCRs is the highest during solar minimum and the lowest during solar maximum (Badhwar and O'Neill 1996). The seasonal variation of electron density profile in the study of Maurya et al. (2012a) shows more significance. The period of study of these authors is under solar minimum; GCRs are important ionizing source and their variation at different season caused the D-region electron density variation (Maurya et al. 2012a). Ohya et al.(2007) indicated that GCR ionization is less intense under solar maximum conditions and the decrease of GCRs due to high solar activities may cause the decrease in the electron density in the D and lower E region of the ionosphere. Since the period of our study is during strong solar activity period of solar cycle 24, the GCRs are not important for the ionization of the nighttime D-region ionosphere. Therefore, the seasonal variation of nighttime D-region electron density due to the variability of GCRs is not significant.

\section{Conclusions}

Recording the tweeks with harmonics $m=1-8$ at Tay Nguyen University, Vietnam (Geog. $12.65^{\circ} \mathrm{N}, 108.02^{\circ} \mathrm{E}$ ), we have found some new rules of the seasonal occurrences of tweeks as well as the seasonal variation of parameters of the nighttime D-region low-latitude ionosphere.

1. Tweeks occur about $51 \%$ during summer season, $22 \%$ during winter season, and $27 \%$ during equinox season. Tweeks with $m=4-8$ occur more often during summer season as compared to winter and equinox seasons. The occurrence rate of the tweeks with the propagation distance in the range of 1000-5000 km during equinox, winter, and summer seasons are 92,89 , and $92 \%$, respectively. The boundary of the waveguide becomes more sharp for tweeks with $m=5-6$.

2. The mean $n_{e}$ increases from $28.4-225.0 \mathrm{~cm}^{-3}$ which corresponds to $h$ of $81.5-87.7 \mathrm{~km}$. During winter season, the variation of $h$ makes a dip around 22:00 LT and has a crest around 3:00 LT and then slightly decreases. During summer season, the temporal variation of $h$ has the crest around 20:30 LT and reduces to the dip from 1:00-2:00 LT and then increases. The $h$ decreases from 19:00-23:00 LT for March and increases from 19:00-21:00 LT for September. The trend of the 
variation of $h$ between 2 months which are in different seasons is nearly symmetric.

3. The $h$ corresponding to higher harmonics ( $m=4-6)$ in the post-midnight is higher during winter and equinox seasons as compared to summer season because $n_{e}$ is lower during winter and equinox seasons than that during summer season. At the higher altitudes, the D-region becomes less inhomogeneous during summer season as compared to that during other seasons; hence, the tweeks with higher modes during summer season could reflect at the less different altitudes, whereas those tweeks during winter and equinox seasons could reflect at the higher altitudes.

4. The mean $h^{\prime}$ during winter, equinox, and summer seasons are $84.4,83.7$, and $83.3 \mathrm{~km}$, respectively. The $\beta$ during winter, equinox, and summer seasons are $0.57,0.55$, and $0.55 \mathrm{~km}^{-1}$, respectively. The $h^{\prime}$ during summer season is lower in our work as compared to other works due to the higher level of solar activity.

5. The values of $n_{e}$ calculated by tweek method during summer, equinox, and winter seasons are lower by $12-58 \%, 3-67 \%$, and $24-76 \%$ than those obtained using the IRI-2012 model, respectively, and show a good comparison with IRI-2012 in the altitude ranges of $82-89 \mathrm{~km}, 87-92 \mathrm{~km}$, and $88-93 \mathrm{~km}$ for summer, equinox, and winter seasons, respectively. The seasonal variation of the electron density profile during solar maximum period shows less significant than that during solar minimum activity period.

\section{Authors' contributions}

LMT analysed the tweek data and and drafted the manuscript. NGT participated in the sequence alignment. TQH participated in explaining the physics processes of the ionosphere and gave many suggestions. QNL participated in the design and coordination and helped to draft the manuscript. All authors read and approved the final manuscript.

\section{Acknowledgements}

The authors are grateful to Department of Physics, Faculty of Natural Science and Technology, Tay Nguyen University for their encouragement and support.

\footnotetext{
Author details

${ }^{1}$ Department of Physics, Faculty of Natural Science and Technology, 567 Le Duan, 632025 Buon Ma Thuot, Vietnam. ${ }^{2}$ Geophysical Center, South Vietnam Geological Mapping Division, 16/9 Ky Dong, Ward 9, District 3, 722923 Ho Chi Minh City, Vietnam. ${ }^{3} \mathrm{Ho}$ Chi Minh City University of Education, 280-An Duong Vuong, Ward 4, District 5, 748342 Ho Chi Minh City, Vietnam. ${ }^{4}$ National Astronomical Observatory of Japan, Chile Observatory, 2- 21-1 Osawa, 181-8588 Mitaka, Tokyo, Japan.

Received: 6 February 2015 Accepted: 19 September 2015 Published online: 05 October 2015

\section{References}

Badhwar GD, O'Neill PM (1996) Galactic cosmic radiation model and its application. Adv Space Res 17(2):7-17

Bremer J, Singer W (1977) Diurnal, seasonal, and solar-cycle variations of electron densities in the ionospheric $D$ and E region. J Atmos Terr Phys 39:25-34
}

Budden KG (1961) The wave guide mode theory of wave propagation. Prentice Hall Press, US

Cannam C, Landone C, Sandler M (2010) Sonic visualiser: an open source application for viewing, analysing, and annotating music audio files. In: Proceedings of the ACM Multimedia 2010 International Conference, Firenze, Italy, 25-29 October, 2010. pp 1467-1468

Cheng Z, Cummer SA, Baker DN, Kanekal SG (2006) Nighttime D region electron density profiles and variability inferred from broadband measurement using VLF radio emission from lightning. J Geophys Res 111, A05302, doi:10.1029/2005JA011308

Cummer SA, Inan US, Bell TF (1998) lonospheric D region remote sensing using VLF radio atmospherics. Radio Sci 33:1781-1792

Dahlgren H, Sundberg T, Andrew BC, Koen E, Meyer S (2011) Solar flares detected by the new narrowband VLF receiver at SANAE IV. S Afr J Sci 107:8

Danilov AD (1998) Solar activity effects in the ionospheric D region. Ann Geophys 16:1527-1533

Friedrich M, Rapp M (2009) News from the lower ionosphere: a review of recent developments. Surv Geophys 30:525-559

Hargreaves JK (ed) (1992) The solar-terrestrial environment. Cambridge Univ. Press, New York

Hayakawa M, Ohta K, Baba K (1994) Wave characteristics of tweek atmospherics deduced from the direction-finding measurement and theoretical interpretation. J Geophys Res 99:10733-10743

Helliwell RA (ed) (1965) Whistlers and related ionospheric phenomena. Stanford Univ. Press, Stanford, California

Kumar S, Deo A, Ramachandran V (2009) Nightime D-region equivalent electron density determined from tweek sferics observed in the south pacific region. Earth Planets Space 61:905-911

Kumar S, Kishore A, Ramachandran V (2008) Higher harmonic tweek sferics observed at low latitude: estimation of VLF reflection heights and tweek propagation distance. Ann Geophys 26:1451-1459

Kumar S, Kumar A (2013) Lightning-associated VLF perturbations observed at low latitude: occurrence and scattering characteristics. Earth, Planets and Space 65(1):25-37

Maeda K-i (1971) Study on electron density profile in the lower ionosphere. J Geomag Geoelectr 23:133-159

Maurya AK, Singh R, Veenadhari B, Kumar S, Cohen MB, Selvakumaran R, et al (2012b) Morphological features of tweeks and nighttime $D$ region ionosphere at tweek reflection height from the observations in the low-latitude indian sector. J Geophys Res 117, A05301, doi:10.1029/2011JA016976

Maurya AK, Singh R, Veenadhari B, Pant P, Singh AK (2010) Application of lightning discharge generated radio atmospherics/tweeks in lower ionospheric plasma diagnostics. J Phys Conf Ser 208

Maurya AK, Veenadhari B, Singh R, Kumar S, Cohen MB, Selvakumaran R, et al (2012a) Nighttime D region electron density measurements from ELF-VLF tweek radio atmospherics recorded at low latitudes. J Geophys Res 117, A11308, doi:10.1029/2012JA017876

Nagano I, Okada T (2000) Electron density profiles in the ionospheric D-region estimated from MF radio wave absorption. Adv Space Res 25:33-42

Ohya H, Nishino M, Murayama Y, Igarashi K (1981) Effects of land and sea parameters on the dispersion of tweek atmospherics. J Atmos Terr Phys 43:1271-1277

Ohya, H, Nishino M, Murayama Y, Igarashi K (2003) Equivalent electron density at reflection heights of tweek atmospherics in the low- middle latitude D-region ionosphere. Earth Planets Space 55:627-635

Ohya H, Shiokawa K, Miyoshi Y (2008) Development of an automatic procedure to estimate the reflection height of tweek atmospherics. Earth, Planets Space 60:837-843

Ohya, H, Shiokawa K, Miyoshi Y (2011) Long-term variations in tweek reflection height in the D and lower E regions of the ionosphere. J Geophys Res 116 , A10322, doi:10.1029/2011JA016800

Ramo S, Whinnery JR, Duzer TV (eds) (1994) Fields and waves in communications electronics, 3rd. John Wiley and Sons, New York

Saini S, Gwal AK (2005) Study of ELF - VLF emisson and tweek atmospherics observed at "Maitri". Ministry of Earth Sciences, Technical Publication No. 22, pp 135-155

Shvets AV, Hayakawa M (1998) Polarization effects for tweek propagation. J Atmos Terr Phys 60:1271-1277

Tan LM, Ha TQ, Thu NN (2014) Observation of the effects of solar flares on the NWC signal using the new VLF receiver at Tay Nguyen University. Sun and Geosphere 80:27-31 
Thomson NR, Clilverd MA, McRae WM (2007) Nighttime ionospheric D region parameters from VLF amplitude and phase. J Geophys Res 112, A07304, doi:10.1029/2007JA012271

Wood GT (2004) Geo-loaction of individual lightning discharges using impulsive VLF electromagnetic waveforms. Dissertation, Stanford Univ. Department of Electrical Engineering

Yamashita M (1978) Propagation of tweek atmospherics. J Atmos Sol Terr Phys 40:151-153

Submit your manuscript to a SpringerOpen ${ }^{\circ}$ journal and benefit from:

- Convenient online submission

- Rigorous peer review

- Immediate publication on acceptance

- Open access: articles freely available online

- High visibility within the field

- Retaining the copyright to your article

Submit your next manuscript at $\boldsymbol{\wedge}$ springeropen.com 